Fecha de recepción: julio 2011

Fecha de aceptación: octubre 2011

Versión final: abril 2012

\section{Repensar la comunicación en las organizaciones. Del pensamiento en línea hacia una mirada sobre la complejidad de las prácticas comunicacionales}

Carina Mazzola *

\begin{abstract}
Resumen: En este trabajo la autora presenta la necesidad de repensar la comunicación en las organizaciones a partir de los nuevos paradigmas científicos, proponiendo desplazamientos conceptuales en las categorías clásicas de análisis de la comunicación.

Realiza un recorrido teórico conceptual sobre la vigencia en los planes corporativos de los modelos de comunicación tradicionales encontrando en ellos, claves de lectura propias del pensamiento de la simplicidad característico de la ciencia clásica del siglo pasado.

A lo largo del artículo propone reconocer que la complejidad de las prácticas de comunicación en las organizaciones requiere de abordajes multidimensionales y transdiciplinarios que reconozcan la otredad y excedan la mera transmisión de información.

Se concluye con un análisis del rol del comunicador en las organizaciones remarcando la necesidad de superar los esquemas difusionistas aplicados tradicionalmente para el diagnóstico y el diseño de acciones de comunicación avanzando hacia nuevas formas de hacer y pensar la comunicación en las organizaciones.
\end{abstract}

Palabras clave: comunicación - comunicación organizacional - información complejidad - paradigmas - prácticas de comunicación - rol del comunicador - simplicidad.

[Resúmenes en inglés y portugués en la página 95]

(*) Licenciada en Comunicación Social por la Universidad Nacional de Rosario (UNR). Integra los claustros docentes de prestigiosas universidades tales como la Universidad de Palermo y la Universidad de Ciencias Sociales y Empresariales (UCES). [Ver CV completo en página 141]

En la medida que el espacio de comunicación se torna cada día más estratégico y decisivo para el bloqueo o desarrollo de nuestras sociedades...se hace más nítida la demanda social de un comunicador capaz de enfrentar la envergadura de lo que su trabajo pone en juego y las contradicciones que atraviesan su práctica (Barbero, 2002).

La propuesta de repensar la comunicación en las organizaciones implica necesariamente navegar al menos una doble complejidad; la inherente a los enfoques conceptuales que guían las prácticas de comunicación y la relativa a las prácticas de quienes trabajan en comunicación en las organizaciones. 
En este sentido, la preocupación por un cambio en los enfoques sobre la comunicación en las organizaciones es creciente y compartida por los nuevos paradigmas científicos de abordaje en la materia que ponen en jaque la preeminencia de una concepción difusionista de la comunicación. Los cambios en los entornos y en la dinámica de las organizaciones han provocado modificaciones en distintos niveles y han dejado insuficientes las categorías clásicas-teóricas y metodológicas- sobre la comunicación en las empresas.

El nacimiento de una sociedad del conocimiento, el afianzamiento de las nuevas tecnología de la comunicación y la información que han replanteado radicalmente la manera en que se produce, se almacena y distribuye el conocimiento modificando las categorías de tiempo y espacio; el surgimiento de generaciones y tribus que habitan en la tecnología, la complejización de los mercados, la proliferación de la información entre otras, han planteado nuevos interrogantes sobre lo que es hacer comunicación en las organizaciones.

De esta manera, los viejos modelos de comunicación que funcionaban como buenas herramientas ya no pueden dar cuenta de preguntas fundamentales como: ¿Por qué los planes de comunicación interna no resuelven las diferencias entre área y niveles? ¿Por qué a pesar del exceso de datos los clientes no poseen información sobre los servicios? ¿Cómo abordar la comunicación en las redes sociales? ¿Por qué no es posible inspirar una visión compartida en el personal a pesar de su difusión? ¿Por qué en la era de la información estamos profundamente desinformados?

Estas nuevas realidades y sus interrogantes nos invitan a repensar las conceptualizaciones sobre comunicación e información y hacen estallar el pensamiento en línea que caracteriza los abordajes sobre comunicación en las organizaciones.

Aunque nadie que trabaje en el área lo reconozca abiertamente, nos hemos acostumbrado a trabajar en comunicación como si esta fuera un proceso de transmisión de mensajes. Es este sentido la mayoría de los planes de comunicación corporativos parten de esta creencia que equipara la información a la comunicación proponiendo la proliferación de diversos mensajes hacia públicos como solución a los problemas detectados. Se trata de un esquema de pensamiento en línea sobre la comunicación que la equipara a la transmisión de datos y que heredamos de los antiguos esquemas sobre la comunicación de masas.

Las razones de lo anterior estriban en una larga tradición teórica en esta clave de lectura hegemónica sobre la comunicación, que ha aportado al comunicador un rol instrumental y un campo metodológico con certezas para la acción.

Bajo esta perspectiva la información desarrollada por la empresa se presenta como única condición para el cambio y la retroalimentación en el espacio de la recepción ocupa el lugar de reaseguro de la comunicación inicial como un círculo cerrado en sí mismo en donde el receptor solo aparece completando un proceso iniciado, tematizado y centralizado desde el lugar de la emisión. De esta manera no es extraño que los mensajes y las estrategias que se desarrollan, por ejemplo para comunicación interna, resulten muchas veces inefectivas: están construidas y pensadas desde la lógica de la emisión, resguardan los intereses de la alta dirección de la organización aportando únicamente prescripciones y recomendaciones que son percibidas como ajenas.

Para ilustrar lo anterior veamos tres casos habituales en comunicación interna: la gestión del House Organ, el buzón de sugerencias y las carteleras institucionales.

La experiencia en el campo de las organizaciones indica que por lo general, los House Organ están construidos en un proceso de comunicación unidireccional, que parte de un emisor que 
decide y valora los contenidos comunicables y un receptor que debe limitarse a informarse sobre los contenidos que otro jerarquiza o evalúa como importantes. A partir de allí es frecuente observar textos eminentemente técnicos que solo le incumben a un segmento de la empresa, informaciones concernientes exclusivamente a realidades de la organización en otros países y hasta revistas elaboradas en otros idiomas.

Como consecuencia de lo anterior, se da un resultado lógico: bajo porcentaje de lectura del House Organ por parte de los recursos humanos, inversión de capital y tiempo que queda en el cesto de basura o cajoneada en una biblioteca. Pero no solamente la pérdida es económica, nada de lo que se hace o no se hace en la organización es neutro, y muchas veces el House Organ aumenta la brecha de distancia entre las diferentes imágenes de la organización, entre la imagen que se plasma en el papel ilustración y aquella que los empleados poseen sobre la empresa.

Por su parte, la gestión del buzón de sugerencias en las organizaciones reviste el mismo tipo de inconvenientes. Por lo general parte de una conceptualización de la comunicación como un producto y no como un proceso lo que implica, por ejemplo, no dar continuidad a aportes de los empleados y no pensar estrategias de apropiación o modificación de la propuesta por parte de los colaboradores a quien va dirigida la estrategia.

A pesar de tratarse de comunicación ascendente, los buzones de sugerencias se construyen desde una lógica centrada en el emisor desatendiendo la complejidad inherente al espacio de recepción. A partir de aquí no se considera por ejemplo si los colaboradores sospechan o no del destino y uso de sus sugerencias, si los empleados sienten que ponen en riesgo sus fuentes de trabajo, si poseen la autoestima suficiente para reconocer que un hallazgo causal o su opinión sobre un proceso puedan ser importantes para la organización, si tienen información o interés para emitir sugerencias...si saben, pueden o quieren hacer sugerencias...en definitiva no tienen en cuenta al otro a la hora de pensar y desarrollar la estrategia comunicacional.

Por su parte la cartelera no es ajena a esta realidad. Es uno de los medios de comunicación que más frecuentemente utilizan las organizaciones ser por económico y de fácil instrumentalización y es frecuente observar en sus procesos de gestión la creencia o sensación, por parte de los responsables de implementarla, de que al publicar informaciones por este medio "han comunicado" liberándose de la responsabilidad de los efectos. A partir de allí se pueden encontrar las siguientes situaciones: carteleras ubicadas en espacios no adecuados para los destinatarios (por ejemplo empresas que las ubican en el comedor restringiendo el tiempo de los empleados de permanencia allí o carteleras en lugares eminentemente de tránsito) carteleras en espacios físicos no visitados por sus destinatarios, mensajes construidos con códigos ajenos a quien se dirigen, contenidos no renovados tales como noticias de años anteriores, comunicados ya vencidos, temas que no tienen interés para los públicos que se dirigen etc.

Los tres ejemplos brindados anteriormente, muestran procesos de comunicación que son vacíos en la instancia de la recepción, que están pensados como una comunicación sin receptor o al menos en uno pasivo y ausente en el desarrollo de la estrategia.

De esta manera, la gestión de la comunicación en las organizaciones sigue mostrando mayoritariamente marcas de racionalidad comunicacional ${ }^{1}$ con claro acento en la linealidad y la verticalidad y con énfasis en los productos más que en los procesos de comunicación. Éstas son marcas que dan cuenta de una forma de concebir la comunicación centrada en la figura del que emite a partir de un proceso que se concibe como unidireccional y de transmisión de un sentido.

Presupone un contrato que acerca y aleja al receptor en el proceso, lo hace pasivo en el formato 
de receptor y activo en el acto de demostrar cambios de conducta o aceptación del dato que se transmite. Propone una relación paradojal, considerando que la recepción de información es condición suficiente pero exige una retroalimentación que pone al otro en la máxima responsabilidad de asumir las consecuencias de la comunicación cuando no ha participado en su proceso. Estas ideas sobrela comunicación la equiparan a la vieja metáfora del canal o del tubo"desarrollado por los modelos matemáticos de la información y por los primeros abordajes funcionalistas sobre la comunicación de masas en EE.UU2 ${ }^{2}$ y resultan hoy, de suma vigencia en los planes de comunicación corporativos.

\section{Una comunicación sin hombres}

"Las organizaciones vivas son fluidas y móviles. Todo intento de inmovilizarlas -en el laboratorio o en nuestra representación- las hace caer en una u otra de las dos formas de muerte: el cristal o el humo" (Atlan, 1990).

Resulta interesante detenernos en la metáfora del canal de comunicación, por el peso simbólico que ha conferido a su definición tradicional y por lo que representa en términos de construcción de la disciplina. La Real Academia Española define al término metáfora como un tropo que consiste en trasladar el sentido recto de las voces a otro figurado en virtud de una comparación tácita. De esta manera la idea de canal de comunicación propia de las primeras teorías de la comunicación, es una metáfora que conecta a la comunicación con el transporte de datos y por ende, la tarea de quienes trabajan en comunicación en un transportador.

Esta idea de comunicación equipara los mensajes a objetos físicos que pueden enviarse y recibirse sin modificar su sustancia y donde fuente y destino son solo dos elementos más en el proceso compuesto por partes individuales interconectadas.

Puesta bajo estudio, la metáfora del canal poco resiste, se desmiembra en nuestras manos con solo contrastarla con la experiencia cotidiana pero sin embargo su vigencia es irrefutable: ¿Cómo creemos en ella?

Desarrollada desde un modelo matemático y científico, se constituyó como la primera forma de "validación científica de la comunicación" sentando los fundamentos de su cientificidad y a pesar de las décadas de evolución sigue estando viva y vigente en la manera en que se piensa la comunicación en diferentes ámbitos.

Heredada por teorías subsiguientes, la metáfora del canal, se transformó entonces en una racionalidad dominante para explicar los procesos de comunicación. Racionalidad que imprime huellas en los modelos de actuación sobre la comunicación definiendo una visión de mundo, un concepto de comunicación y de hombre que resulto perfecto para un paradigma de ciencia imperante.

En este sentido, la metáfora del canal cargó desde sus inicios con todo el peso de un pensamiento simplificador propio de los abordajes ciencia clásica y le confirió a la disciplina un estatuto científico. Le permitió a la comunicación instalarse como un saber válido donde el conocimiento se piensa como observable, objetivable, factible de medir y demostrar.

Morin reconoce que la ciencia clásica se fundó bajo el signo de la objetividad configurando un universo constituido por objetos aislados en un espacio y tiempo neutro y sometido a leyes 
objetivamente universales. Sostiene que en esta visión, el objeto científico existe sin que el observador participe en su construcción con las estructuras de su entendimiento y las categorías de su cultura (Morin, 1977).

De esta manera, el pensamiento de lo simple construyó una ciencia de los objetos aislados, demarcados y separados por bordes disciplinares, objetos escindidos de la realidad, parcelados y gobernados por disciplinas en compartimentos estancos. Trajo consigo una perspectiva epistemológica que equiparó las ciencias sociales a las ciencias duras y propuso una única forma de conocer sostenida por el conocimiento objetivable.

Esta visión lineal de los procesos de comunicación volvió invisible una cosmovisión del hombre en tanto sujeto de cambio, lo partió en fragmentos disciplinares e impulsó el repliegue de un sujeto con corporalidad y emocionalidad en integración con su ambiente.

Denisse Najmanovich plantea al respecto del pensamiento sobre lo simple: "la mirada de la simplicidad tiene elementos aislados al vacío: unidades inmutables y eternas, límites limitantes, independencia, espacio abstracto, relaciones fijas no transformadoras, determinismo y sistemas mecánicos cerrados" (Najmanovich, 2008).

Cada uno los elementos que describe Najmanovich, puede identificarse en la metáfora del canal de comunicación: la descomposición del objeto de estudio hasta llegar a partículas elementales, un tiempo y espacio no situado ajeno a la historia y a los hombres, partes independientes que son susceptibles a ser aisladas y un sistema que se cierra sobre si mismo evitando cualquier tipo de transformación que lo ponga en riesgo buscado de manera imperante el control sobre sus elementos.

De esta manera aparecen las tradicionales categorías de análisis de la comunicación (emisor, mensaje, receptor, canal, código, retroalimentación etc.) y lo comunicacional se transforma en un objeto de estudio racional, sin tiempo y sin espacio que puede ser aislado del hombre para ser estudiado, analizado y medido.

Esta concepción de la comunicación generó una dimensión teórica y metodológica de abordaje de lo comunicacional proponiendo instrumentos para su estudio. Al respecto del carácter estructurante de la ciencia, Fabri (1993) plantea que el discurso científico no se limita a analizar la realidad, sino que construye un objeto propio a partir de los discursos científicos precedentes y de los que vendrán, de tal manera que vuelve sobre sí mismo construyendo su propia validez. Puesta como piedra fundacional la metáfora del canal ejerció un rol estructurante en las teorías subsiguientes y por ende en los abordajes metodológicos en la materia.

Las marcas de racionalidad que permiten reconocer esta concepción de la comunicación en las organización pueden identificarse claramente: marcadas divisiones e incongruencias entre la comunicación interna, externa y las comunicaciones de marketing que responden muchas veces a lógicas diferentes, el hecho de pensar que lo "comunicacional" es responsabilidad excluyente de un área, la mirada instrumental sobre la comunicación que se traduce en planes de comunicación lineales, la falta de participación y consideración del espacio de recepción en las estrategias, la equiparación de la información a la comunicación, son algunos de los signos que muestran la preeminencia de esta concepción de comunicación en las organizaciones.

Abandonar la visión lineal sobre la comunicación se transforma en una necesidad imperiosa, un esfuerzo de integrar los fragmentos disciplinares en un diálogo plural que devuelva el hombre al hombre y a la comunicación a su carácter de transformación 


\section{Abrir la comunicación: un retorno al otro}

"Debemos hacer todo lo posible para desarrollar nuestra racionalidad, pero en ese mismo desarrollo la racionalidad reconoce los límites de la razón, y realiza el diálogo con lo no racionalizable" (Morin, 2001).

En la frase de inicio de este apartado, Morin nos invita a pensar la realidad desde su complejidad, a superar los límites y las carencias de un pensamiento simplificador hegemónico en la ciencia para abordar un conocimiento multidimencional que se observe en sus propios límites. Desde esta concepción, la comunicación es mucho más que una cuestión de mensajes porque expresa las vincularidades entre diferentes. Los seres humanos somos seres complejos que establecemos relaciones multidimensionales más allá de la información que recibimos.

Es posible reflexionar sencillamente sobre la complejidad de la comunicación analizando el vínculo que se establecen entre compañeros de trabajo. Cada día comparten, palabras, gestos, charlas, consignas, papeles escritos, comportamientos. Por cada jornada que trabajan juntos intercambian cientos de unidades de información que incluyen lo dicho y lo de dicho, aquello que se verbaliza y aquello que se actúa. Y esa relación está enmarcada en una historia del vínculo, en un contexto que condiciona la forma de comunicación que hay entre ellos. Cada uno de ellos ve la vida de manera diferente, parte de diferentes intereses, posee diversas necesidades sobre su lugar en la empresa, consideran que los conflictos tienen raíces diversas .Frente a esto: ¿Es posible circunscribir la comunicación solo a la transmisión de información? ¿Se sostiene la creencia de que los conflictos de comunicación se resuelven solo a partir de transmitir datos? Otro ejemplo en el terreno de las organizaciones puede ayudarnos a pensar en la complejidad de los intercambios comunicativos y en como las herramientas del pensamiento de lo simple no resultan suficientes para comprender la complejidad.

Si consideramos un eje común de las campañas de prevención de accidente en el trabajo, encontraremos por lo general que las prácticas de comunicación se reducen al uso de carteleras, boletines internos e Intranet donde se emiten mensajes preventivos que buscan ser persuasivos e interpelar a los sujetos a cambios de prácticas. Frases como "cuide a su familia: use el casco" o "prevenir accidentes es una responsabilidad de todos" son solo ejemplos de frases frecuentes de encontrar en estos casos que guardan en común la creencia de que la información es condición para el cambio de conducta.

Sin embargo, mirar la situación desde el prisma de la complejidad implica considerar que el no uso de las medidas de seguridad puede erigirse como un espacio de resistencia frente a un discurso hegemónico, puede constituir una práctica de diferenciación con respecto a otros grupos dentro de la empresa (situación muy común en los mandos medios) puede considerarse como una práctica incómoda para el trabajo, puede estar vinculada a sentimientos tales como ser condescendiente o poco masculino entre las infinitas posibilidades de significación que se construyen en cada entorno o situación dada.

Por su parte y del "otro lado" al analizar la instancia de emisión, veremos ponerse en juego lógicas y racionalidades propias, códigos, recursos que responden a claros intereses y a una posición y concepción particular de la situación problema que se aborda que no necesariamente es coincidente con la manera en que los trabajadores conceptualizan los problemas de prevención de accidentes sobre los cuales deben preservarse. ${ }^{3}$ 
Los dos ejemplos volcados anteriormente nos permiten ilustrar como el pensamiento tradicional en línea no permite abordar la complejidad de los vínculos, sino por el contrario, niega la complejidad para reconocer relacionales causales, simples y lineales que unen a personas con comportamientos.

$\mathrm{Al}$ respecto de la complejidad de los vínculos que se produce en lo comunicativo, Rosa María Alfaro plantea "Así no hay sujetos pasivos siempre media una relación activa, adquiriendo sentido la palabra, el cuerpo y las imágenes desde la que todos hablan y escuchan mutuamente, incluso a través del silencio" (Alfaro, 1993).

De esta manera, Alfaro marca el carácter de construcción permanente que se da en la comunicación, donde emisores y receptores se construyen en un proceso a partir de las múltiples identidades, los modos, lo dicho y lo no dicho que se tejen desde la trama de la vida cotidiana donde cada actor participa y construye la comunicación.

Desde los nuevos paradigmas, lo comunicacional comienza a ser entendido como un espacio de encuentro de saberes diversos y se marca la necesidad de inscribir las prácticas de comunicación en un aquí y ahora. Se empieza incorporar lo "no racionalizable" que propone Morin en términos de subjetividad, emocionalidad y particularidad en cada situación y se marcan los límites de transpolar experiencias o aislar el problema en unidades simples.

Se busca una nueva mirada sobre la comunicación, que no fragmente ni muestre relaciones lineales, que no busque causas y efectos en un tiempo en línea, que mire al otro como diferente, integral, complejo, sin divisiones. Que reconozca el conflicto como inherente a la articulación social y no intente resolverlo sino abordarlo. Que parta de valorar al otro, pero no como otro "descafeinado" o "light" sino como un otro verdaderamente diferente en su esencia al cual no tengo la pretensión de intentar cambiar.

Esta concepción de comunicación implica replantear la categoría clásica de receptor para hablar de actores sociales no escindidos en un proceso de comunicación. Hablamos de actores sociales y no de meros receptores porque ya no se trata de un sujeto-objeto que decodifica un mensaje aportándole un sentido individual sino de actores sociales en múltiples roles y atravesamientos. Atravesamientos de género, social, cultural, educativo, histórico, económico, sindical, que configuran un espacio de recepción múltiple desde donde se ejerce la resistencia y la diferencia en un proceso de poder y de negociación. Actores sociales que comunican a través de sus prácticas más allá de lo que dicen con palabras y que entran y salen de los procesos de comunicación ejerciendo diferentes roles.

A partir de allí coincidimos con Washington Uranga en definir la comunicación como "un proceso social de producción, intercambio y negociación de formas simbólicas, fase constitutiva del ser práctico del hombre y del conocimiento que de allí se deriva" y continua diciendo "la comunicación se define por la acción" porque es "a través de nuestras acciones (que) vamos configurando modos de comunicación". Pero, al mismo tiempo, "la comunicación que hacemos de nuestra acción, el lenguaje que utilizamos, constituye el sentido y el contenido de nuestra acción" (Uranga, 2006).

Entonces ya no se trata de "alcanzar a otro con un mensaje efectivo", ya no se trata solamente de pensar en mensajes persuasivos, sino se trata de leer sus prácticas, de buscar espacios de encuentro donde nos reconozcamos y respetemos como diferentes y a partir de allí busquemos los puntos que nos conectan para trabajar juntos en post de una meta que desde cada interés particular, se presenta como compartida. 


\section{Nuevos roles para habitar la incertidumbre}

Es interesante iniciar este apartado haciendo alusión a las cartografías cognitivas de Martín Barbero (1993). En efecto, después de encorsetar la comunicación en sus técnicas y en los medios, la idea de centrar la labor de comunicación en cartografías parece tranquilizadora en la medida que presenta la transmisión de mensajes solo como una pequeña parte del territorio. El rol del comunicador puesto en el lugar de cartógrafo permite ampliar la mirada sobre la comunicación y habilitar planteamientos más diversos aunque no carentes de paradojas y contradicciones.

Y este último punto es fundamental en la labor de quienes trabajamos en comunicación; habitamos las contradicciones, construimos nuestro trabajo en la incertidumbre y por primera vez en siglos de tradición científica; podemos reconocer que esta incertidumbre es inherente y emerge de nuestro accionar porque trabajamos en procesos en continuo movimiento.

La incertidumbre hace emerger lo imprevisto porque la consideración de la otredad implica cobijar la posibilidad de lo no esperado ya que implica reconocer una subjetividad que no es la propia y por tanto desconozco.

Mariana Piola, en el texto "Cuatro roles y un compromiso ético para el comunicador" propone un enfoque epistemológico con el objeto de "construir de una mirada donde el comunicador entienda el fenómeno sobre el que trabaja como complejo y multidimensional, que lo proyecte en el futuro con libertad pero que confíe en la estrategia como modo de compresión y eterna incertidumbre" (Piola, 2009). A partir de aquí, la autora propone cuatro roles en la tarea de comunicación: el rol de analista-deconstructor, el gestor del conocimiento, el generador constructor y el animador.

Cada uno de los roles ejerce una tarea productora; el rol de analista constructor produce inteligibilidad para la acción, el rol de gestor del conocimiento produce conocimiento del proceso en movimiento, el rol de animador produce participación y el rol de generador-constructor desarrolla productos insertos en procesos de comunicación. Para la autora, son cuatro roles y un compromiso ético centrado en las articulaciones que hacen a la especificidad de la comunicación. La mirada de Piola resulta interesante porque permite pensar en la tarea de comunicación en las organizaciones en roles que navegan entre dimensiones analítica y fácticas considerando ambas tareas de manera productiva logrando romper la idea tradicional que asocia la labor en comunicación a los medios otorgándole un lugar instrumental. Introduce la incertidumbre como variable de trabajo rechazando los enfoques tradicionales que ofrecen fórmulas y garantías.

Desde estas perfectivas la tarea de quienes trabajan en comunicación se trata de un espacio por crear en cada organización, se erige como un desafío, un lugar para comenzar a tejer tramas de posibilidad de encuentro entre las personas.

La tarea del comunicador implica en términos de Uranga

construir una trama de sentidos que involucra a todos los actores, sujetos individuales y colectivos en un proceso de construcción también colectivo que va generando claves de lectura comunes, sentidos que configuran modos de entender y de entenderse, modos interpretativos en el marco de una sociedad o una cultura (Uranga, 2007). 
La tarea de quienes hacemos comunicación se asemejará a realizar un tejido, reconociendo los diferentes hilos, valorando las particularidades y desarrollando a partir de allí una trama común que vincula a los actores en una labor conjunta.

El trabajo de la comunicación implica movilizar procesos que incorporen el conocimiento circulante a la producción de nuevo conocimiento incorporando una nueva temporalidad que considere los aspectos del pasado (por ejemplo la historia de la organización) y aspectos del presente (por ejemplo la situación problema a abordar) como elementos que confluyen y se imbrindan para determinar que una situación problemática se erija como tal. Estos serán elementos claves para considerar en el diagnóstico y actuación sobre la comunicación organizacional. Trabajar hoy en comunicación implica aceptar que la complejidad inherente a la realidad no puede ser abordada por un solo campo disciplinar ni alcanzada por un mensaje y que requiere de profesionales capaces de afrontar la transdisciplina y trasformarse en sintonía con la realidad que desean cambiar. Es justamente en la complejidad de esos encuentros donde aparece la necesidad de transgredir los límites disciplinares para construir nuevos niveles de comprensión. La complejidad exige a quienes trabajan en comunicación integrar equipos interdisciplinarios que sean capaces de abordar problemas más allá de los campos delimitados de las disciplinas aportando soluciones complejas a problemas complejos.

Eduardo Vizer nos indica: "la comunicación puede ser precisamente una perspectiva de interpretación que cruce los límites disciplinarios y ayude a construir un metanivel de comprensión sobre la realidad conflictiva y multidimensional de los procesos que se articulan en una realidad dada" (Vizer, 2003).

Desde estas perspectivas, la tarea de quienes trabajan en comunicación se ubica en los cruces y en los bordes. Cruces y bordes entre saberes, prácticas, sujetos, luchas de poder, espacios y disciplinas que se abren en sus propios límites para afrontar la complejidad.

\section{Notas}

1. El concepto de marcas de racionalidad fue desarrollado por Massoni, S. (2007) y da cuenta de la concepción teórica que está presente en una situación de comunicación. Desde esta perspectiva, la autora considera que "cada teoría opera en distintas dimensiones del fenómeno comunicacional y al hacerlo le imprime su racionalidad, su proyecto. Es posible interpelar situaciones de comunicación para rastrear estas marcas de racionalidad, que son índices de la concepción teórica que está organizando/ articulando/ la racionalidad del encuentro" (Massoni, 2003).

2. En 1948 E. Shannon publica su reconocida teoría matemática de la comunicación (Mathematical Theory of Communication', Bell System Technical Journal, 1948). A partir de equiparar la comunicación humana al telégrafo, descompone el acto de comunicación en elementos y propone el concepto de entropía para medir la eficacia de un canal. El trabajo de Shannon es reconocido como una piedra fundacional de la comunicación aportándole reconocimiento científico de la disciplina. Por su parte, Lasswell H. desarrolla en el mismo año el texto "Estructura y función de la comunicación en la sociedad" donde delimita los campos de estudio de la disciplina y desarrolla el conocido esquema de preguntas para abordar la comunicación. Dicho esquema trascenderá más allá de los abordajes funcionalistas sobre la comunicación de masas 
para ser estructurante del discurso científico posterior en la materia.

3. Para más información sobre la relación entre comunicación y prevención de accidentes en el trabajo ver el artículo desarrollado en coautoría con Lorena Steinberg "Comunicación para la prevención de riesgos" disponible en: http://www.procomunicar.com.ar/cprev1.htm

\section{Referencias Bibliográficas}

Atlan, H. (1990). Entre el cristal y el humo. Madrid: Ed. Debate.

Alfaro Moreno, R. S. (1993). La comunicación como relación para el desarrollo. Una comunicación para otro desarrollo. Lima: Calambria.

Barbero, M. (2002). Oficio de cartógrafo. Santiago de Chile: Fondo de Cultura Económica. (1993). De los medios a las mediaciones. Barcelona: Gustavo Gili (3º ed).

Fabri, P. (1993). Reflexiones acerca de la comunicación y el discurso científico, en Comunicación, discursos y semióticas. Rosario: UNR Editora.

Massoni, S. (2007). Estrategias. Los desafíos de la comunicación en un mundo fluido. Colección Comunicación. Rosario: Homo Sapiens.

Morin, E (2001). Amor, poesía, sabiduría. Barcelona: Seix y Barral.

(2001). Introducción al pensamiento complejo. Barcelona: Gedisa (5a ed).

(1977). El Método. Tomo I. La Naturaleza de la Naturaleza. Paris: Seuil. Col. Points.

Najmanovich, D. (2008). La organización en redes de redes y de organizaciones. FISEC-Estrategias. Año V, Número 11.

Piola, M. (2009). Cuatro roles y un compromiso ético para el comunicador. Prospectiva y estrategia para navegar en la complejidad. En, A.A.V.V. Impresiones desde la comunicación. Ensayos sobre cultura y organizaciones contemporáneas. Buenos Aires: Dunken.

Uranga, W. (2008). Prospectiva estratégica desde la comunicación. Una propuesta de proceso metodológico de diagnóstico dinámico y planificación. Buenos Aires.

(2007). Mirar desde la comunicación. Buenos Aires. Disonible en: http://www.catedras.fsoc.uba. ar/uranga/uranga_mirar_desde_la_comunicacion.pdf

(2006). El cambio social como acción transformadora, en Enz, A. y otras (editoras). Comunicar para el cambio social. Buenos Aires: La Crujía Ediciones - Comunia. Disponible en: http:// www.catedras.fsoc.uba.ar/uranga/prospectiva_comunicacion_mayo_08.doc

(2001). Una propuesta académica con la mirada puesta en la prácticas sociales. En, PLANGESCO, Maestría en Planificación y Gestión de Procesos Comunicacionales, Documento curricular y plan de estudios. La Plata: FPyCS-UNLP.

Vizer, E. (2003). La trama (in) visible de la vida social. Comunicación, sentido y realidad. Buenos Aires: La Crujía Ediciones. 


\begin{abstract}
Summary: In this article, the author proposes to rethink organizational communications from the new scientific paradigms, proposing conceptual displacements in the classic categories of communication analysis. She makes a theoretical route in order to describe how effective corporate plans based on traditional models of communication are, finding in them, reading keys owned by the thought based on simplicity which was characteristic of the classic science of the past century. Throughout the article the author proposes to recognize that the complexity of the communication practices in the organizations requires both multidimensional and transdiciplinary approaches that recognize the others and exceed the mere transmission of information. The work concludes with an analysis of the role communication people in the organizations observing the need to surpass the difusing schemes traditionally applied for the diagnosis and the design of communication action advancing towards new forms to make and to think the communication in the organizations.
\end{abstract}

Key words: communication - communicator role - information complexity - organizational communication - paradigms - practices of communication - simplicity.

Resumo: Neste escrito, a autora apresenta a necessidade de repensar a comunicação nas organizações a partir dos novos paradigmas científicos, propondo deslocações conceituais nas categorias clássicas de análisse da comunicação.

Faz um percurso teórico conceitual sobre a vigência nos planos corporativos dos modelos de comunicação tradicionais encontrando neles chaves de leitura próprias do pensamento da simplicidade característico da ciência clássica do século passado.

Ao longo do artigo propõe reconhecer que a complexidde das práticas de comunicação nas organizações requerem de abordagens multidimensionais e transdisciplinares que reconheçam a outridade e exedam da mera transmição de informação.

O escrito conclui com uma análisse do papel do comunicador nas organizações remarcando a necessidade de superar os esquemas difusionistas utilizados tradicionalmente para o diagnóstico e geração de accões de comunicação avançando até novas maneiras de fazer e pensar a comunicação nas organizações.

Palavras chave: complexidade - comunicação - comunicação organizacional - informação paradigmas - papel do comunicador - práticas de comunicação - simplicidade. 